\title{
Evolution of Remnant State Variables and Linear Material Moduli in a PZT Cube under Compressive Stress at Room and High Temperatures
}

\author{
Dae Won Ji and Sang-Joo Kim ${ }^{\dagger}$ \\ Department of Mechanical and Information Engineering, University of Seoul, Seoul 130-743, Korea \\ (Received November 7, 2012; Revised December 27, 2012; Accepted January 9, 2013)

\section{상온과 고온에서 압축하중을 받는 PZT에서의 잔류상태변수와 선형재료상수의 변화} \\ 지대원 - 김상주 ${ }^{\dagger}$ \\ 서울시립대학교 기계정보공학과
}

(2012년 11월 7일 접수 ; 2012년 12월 27일 수정 ; 2013년 1월 9일 채택)

\begin{abstract}
A poled lead zirconate titanate (PZT) cube specimen is subjected to impulse-type compressive stress with increasing magnitude in parallel to the poling direction at four room and high temperatures. During the ferroelastic domain switching induced by the compressive stress, electric displacement in the poling direction and longitudinal and transverse strains are measured. Using the measured responses, linear material properties, namely, the piezoelectric and elastic compliance coefficients, are evaluated by a graphical method, and the effects of stress and temperature are analyzed. Finally, the dependency of the evaluated linear material properties on relative remnant polarization is analyzed and discussed.
\end{abstract}

Key words : PZT, Ferroelastic switching, Remnant polarization, Linear moduli, Temperature

\section{1. 서 론}

압전세라믹 재료는 감지기나 작동기 같은 다양한 분야 에 사용되는 재료이다. 그러나 사용되는 동안 자체발열이 나 외부의 고온으로 인하여 감지기나 작동기의 온도가 과 격하게 증가하는 경우가 있다. 또 과도한 응력으로 도메 인 스위칭이 발생하여 내부구조가 변하고 그 결과 압전 시스템의 성능이 악화되는 경우가 있다. 이러한 내부구조 의 변화가 거시적으로는 비선형 거동으로 나타나며 따라 서 비선형 거동을 예측할 수 있는 모델링 연구가 중요하 다. 최근 스위칭으로 인한 압전재의 비선형 거동을 예측 할 수 있는 모델을 개발하는 연구가 활발히 이루어졌다. ${ }^{1,2)}$ 스위칭 할 수 있는 압전세라믹 재료의 비선형 거동에 대한 신뢰성 있는 모델을 개발하기 위하여 온도와 압축 응력의 크기에 따른 비선형 거동 특성에 대한 실험적 관 찰과 분석이 필요하다. 상온과 고온에서 압전재의 비선형 거동에 대한 실험 연구는 다양하게 이루어져 왔다. Webber

${ }^{\dagger}$ Corresponding author : Sang-Joo Kim

E-mail : sangjookim@gmail.com

Tel : +82-2-2210-2757 Fax : +82-2-2210-5575 et $\mathrm{all}^{3}{ }^{3)}$ 은 고온에서 압전세라믹이 큰 압축하중을 받을 때 의 비선형 거동을 관측하고 강유전 스위칭과의 관계를 분 석하였으며, Selten et al. ${ }^{4}$ 은 상온에서 전기장에 의한 스 위칭이 발생할 때 선형재료상수의 변화를 관측하였다. Liu and Huber ${ }^{5}$ 와 Zhou et al. ${ }^{6}$ 은 압축하중과 전기장이 작용 하여 스위칭이 발생할 때 여러 가지 선형재료상수들의 변 화를 구하여 잔류분극(remnant polarization)이나 잔류변형 률(remnant strain)과 같은 잔류상태변수에 대한 의존성을 연구하였다. 그 외에도 최근 상온뿐만 아니라 고온에서 전기장과 압축응력을 받아 압전세라믹에서 스위칭이 발 생할 때 선형재료상수의 변화를 구하여 잔류 상태변수에 대한 의존성을 분석하는 연구가 활발히 이루어졌다. ${ }^{7-10)}$

본 연구에서는 최근에 이루어진 연구의 연속선상에서 상온과 고온에서 충격파 형태의 압축 응력을 받아 스위 칭이 발생할 때 압전시편의 전기밀도와 변형률들을 계측 하고, 압전계수와 탄성유연계수의 변화를 구한 후 잔류상 태변수에 대한 의존성을 분석하였다.

\section{2. 실험방법}

한 변의 길이가 $10 \mathrm{~mm}$ 인 정사각형 단면에 전극처리가 


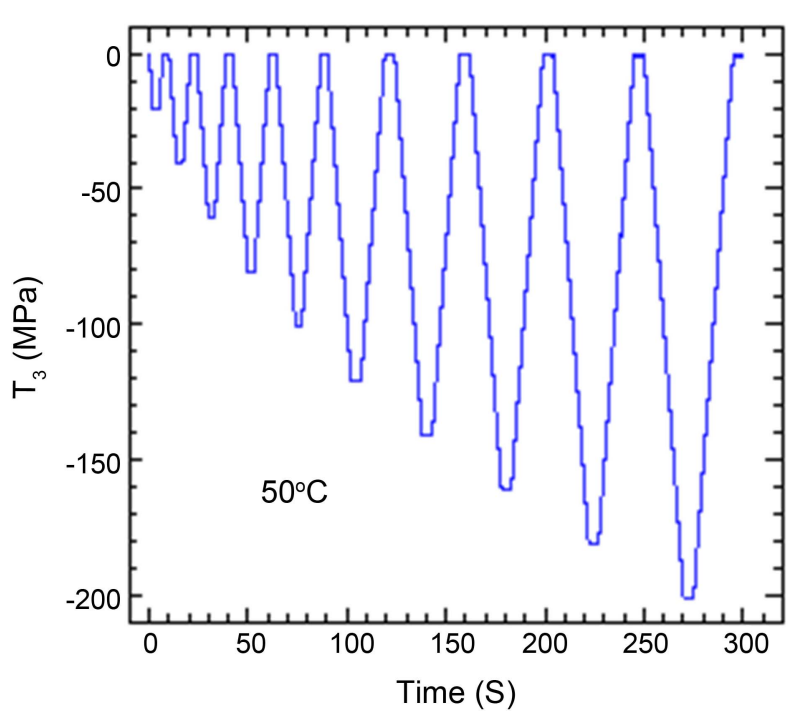

Fig. 1. Compressive stress of impulse type with increasing magnitude plotted versus time at $50^{\circ} \mathrm{C}$.

되어 있고 $12 \mathrm{~mm}$ 인 두께방향으로 분극처리 되어있으며 밀도가 $7400 \mathrm{~kg} / \mathrm{m}^{3}$ 인 PZT 시편 (PZT5H1, Morgan Technical Ceramics, UK)에 압축응력이 작용한다. 압축응력은 두께 방향으로 작용하며 그 결과 시편의 두께 방향 (또는 길이 방향)으로의 분극밀도와 길이방향 및 길이에 수직한 횡방 향으로 변형이 발생하게 된다. 압축응력이 충분히 클 경 우 분극의 크기가 점점 작아지면서 비선형적인 거동이 발 생하고 그 결과 재료의 특성이 변하게 된다. 압축하중 인 가에 따른 도메인 스위칭과 재료의 특성변화의 관계를 이 해하기 위하여 압축하중은 Fig. 1에 보인 바와 같이 충격 하중의 형태로 인가된다. 충격파의 크기는 $20 \mathrm{MPa}$ 에서 $200 \mathrm{MPa}$ 까지 시간에 따라 점점 더 증가하게 된다.

각 충격파에서 압축응력의 증가 및 감소 속도는 초당 $5 \mathrm{MPa}$ 이며 목표응력에 도달한 후 또 충격파와 충격파 사이에 각각 약 2,3 초의 시간이 주어진다. 압축하중 인 가는 $20^{\circ} \mathrm{C}$ 뿐만 아니라 $50^{\circ} \mathrm{C}, 80^{\circ} \mathrm{C}, 110^{\circ} \mathrm{C}$ 에서 각각 이루 어진다.

압축응력 충격파의 크기가 $200 \mathrm{MPa}$ 까지 증가하는 동안 시편의 두께 (또는 길이) 방향으로의 전기밀도 $D_{3}$, 길이 및 횡방향으로의 변형률 $S_{3}, S_{1}$ 을 측정한다. 전기밀도는 Sawyer-Tower 회로를 이용하여 간접적인 방법으로 측정 하며 시편과 직렬 연결된 커패시터에 걸리는 전압을 측 정하기 위해서 Keithley 6514를 사용한다. 변형률은 시편 의 측면에 부착된 스트레인 게이지 (WA-03-062TT-350, VISHAY, Germany)를 이용하여 측정하는데 $-75^{\circ} \mathrm{C}$ 부터 $205^{\circ} \mathrm{C}$ 까지 사용가능하며 온도보상이 되는 게이지이다. 시 편의 온도조절은 시편을 절연유 (MICTRANS Class1-No2, MICHANG OIL IND. CO., Pusan, Korea)가 들어 있는 Fig. 1에 보인 용기 (2408 PID controller, EUROTHERM,

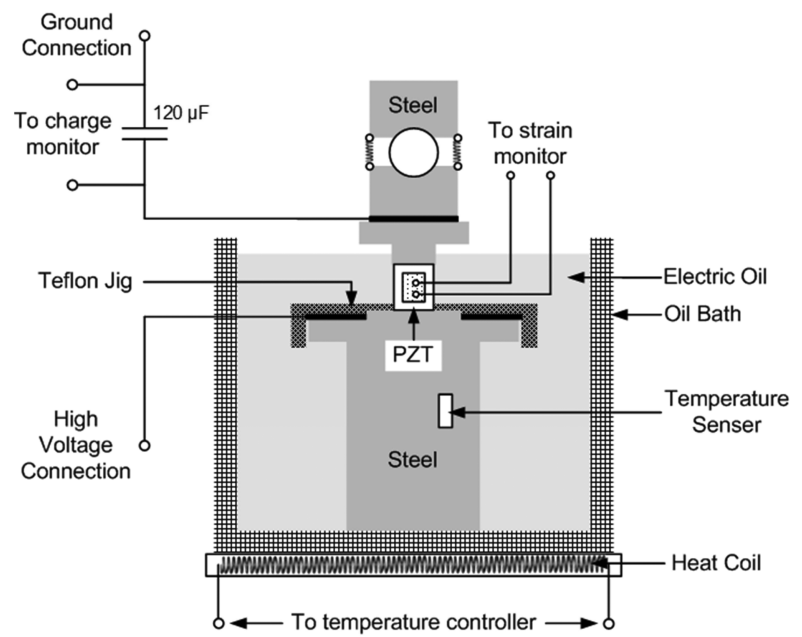

Fig. 2. Experimental set up for measuring electric displacement and strains of a poled PZT cube under impulsive compressive stress at room and high temperatures.

$\mathrm{UK})$ 에 넣고 절연유의 온도를 용기 밑에 있는 코일에 의 하여 조절함으로써 이루어진다.

모든 데이터는 $100 \mathrm{~Hz}$ 로 수집되며 수집된 데이터는 데 이터 처리 기판 (PCI 6221, National Instruments, TX, $\mathrm{USA}$ )을 통과하여 랩뷰(LABVIEW) 프로그램으로 처리된다.

제조사에서 제공한 시편의 주요특성은 다음과 같다. 큐 리점은 $200^{\circ} \mathrm{C}$, 커플링 팩터 $k_{p}=0.60$, 압전계수 $d_{31}=$ $-250 \times 10^{-12} \mathrm{C} / \mathrm{N}, d_{33}=620 \times 10^{-12} \mathrm{C} / \mathrm{N}$, 탄성 유연 계수는 $s_{33}=21.9 \times 10^{-12} \mathrm{~m}^{2} / \mathrm{N}, \mathrm{s}_{11}=17.7 \times 10^{-12} \mathrm{~m}^{2} / \mathrm{N}$ 이다. 여기서 하첨자 3 은 시편의 분극 방향, 하첨자 1 은 분극에 수직한 방향을 나타낸다. 서로 다른 온도에서의 분극처리 상태를 결정하기 위하여 기준온도인 $20^{\circ} \mathrm{C}$ 의 분극처리된 상태에 서 외부의 전기장이나 응력이 작용하지 않는 채로 온도 를 올린다. 온도에 따른 분극밀도와 변형률의 변화를 측 정하였으며, $50^{\circ} \mathrm{C}, 80^{\circ} \mathrm{C}, 110^{\circ} \mathrm{C}$ 에서의 분극 밀도를 기록 한다. $\mathrm{Ji}$ and $\mathrm{Kim}^{10)}$ 에 의하면 $20^{\circ} \mathrm{C}, 50^{\circ} \mathrm{C}, 80^{\circ} \mathrm{C}, 110^{\circ} \mathrm{C}$ 에서의 분극처리 상태에 해당하는 분극 밀도의 값은 각 각 $-0.52,-0.49,-0.45,0.41 \mathrm{C} / \mathrm{m}^{2}$ 이다. 어떤 한 온도에서 압축하중 실험을 수행할 때, 그 온도에서의 분극처리 상 태에 해당하는 분극밀도를 전기장을 인가하여 얻은 후에 압축하중 실험을 수행한다. 각 온도에서 원하는 분극처리 상태를 얻기 위해 인가되는 전기장은 각각 $1.0,0.9,0.783$, $0.617 \mathrm{MV} / \mathrm{m}$ 이다.

\section{3. 결과 및 고찰}

\section{1. 압전계수와 탄성유연계수의 결정}

Fig. 1 에 보인 바와 같은 충격파 형태의 압축하중이 $50^{\circ} \mathrm{C}$ 에서 작용할 때 시편에 발생하는 전기밀도 $D_{3}$ 와 종방향 및 횡방향 변형률 $S_{3}, S_{1}$ 의 변화가 각각 Fig. 3(a)과 (b)에 


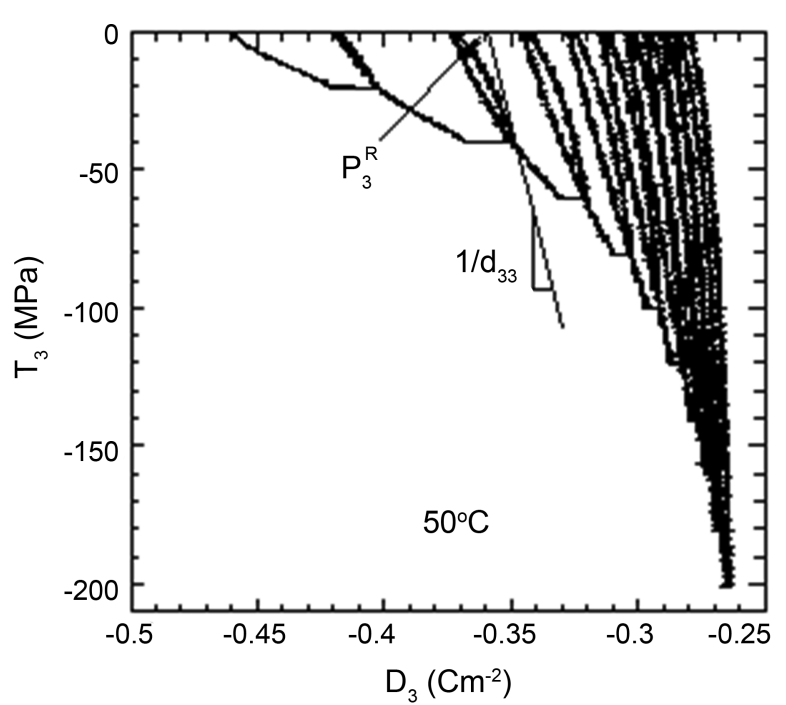

(a)

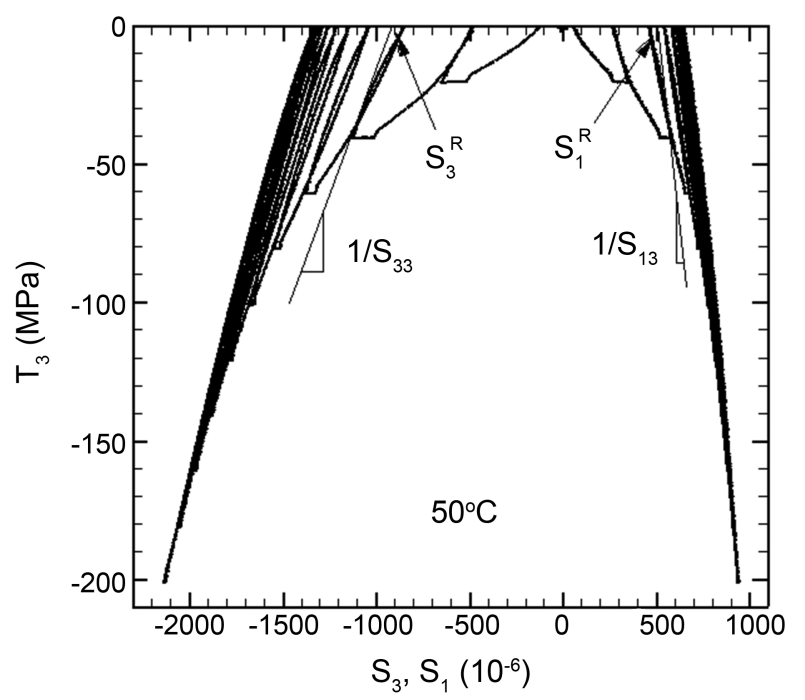

(b)

Fig. 3. Measured (a) electric displacement and (b) longitudinal and transverse strain curves during compressive stress loading at $50^{\circ} \mathrm{C}$, and evaluations of piezoelectric coefficient and compliance coefficients.

있다. 압축응력의 크기가 $40 \mathrm{MPa}$ 에 도달한 후 감소하기 시작하는 순간에 전기밀도와 종방향 변형률, 횡방향 변형 률 선도에서의 접선을 그렸다. 그 접선의 기울기는 각각 $1 / d_{33}, 1 / s_{33}, 1 / s_{13}$ 와 같으며 그 기울기로부터 구한 선형재 료상수는 각각 그 순간의 재료의 도메인 구조에 대응하 는 압전계수와 탄성유연 계수라고 간주할 수 있다. 구한 재료상수에 대응하는 재료의 도메인 구조를 나타내는 상 태변수로서 이용되는 잔류분극 $P_{3}^{R}$ 과 잔류변형률 $S_{3}^{R}$ 의 값은 Figs. 3(a)과 (b)에 화살표로 나타낸 바와 같이 접선 과 수평축과의 교점을 읽어서 구할 수 있다.

재료상수는 응력이 감소하기 시작하는 순간에 뿐만 아 니라 응력이 0 에서부터 증가하기 시작하는 순간에도 비

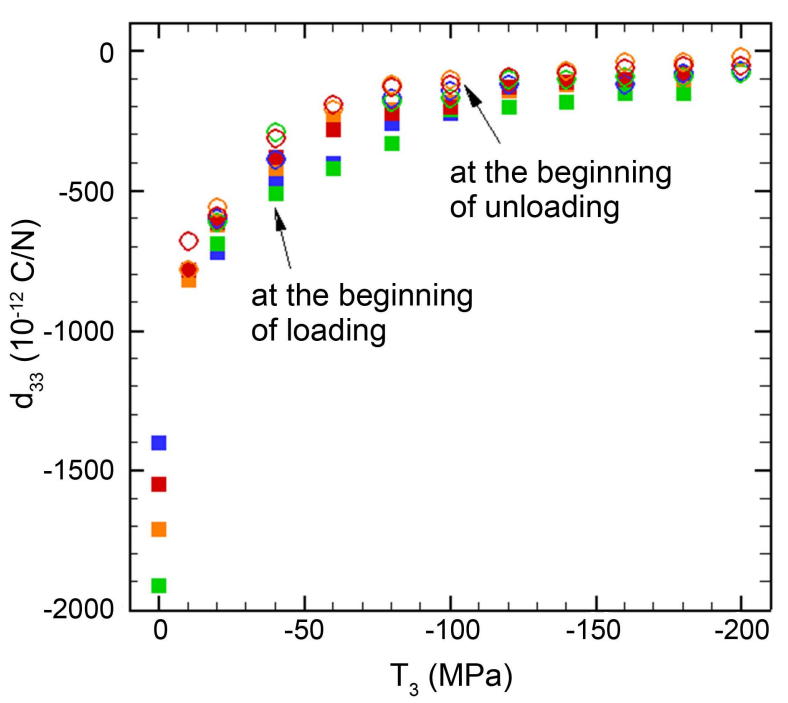

(a)

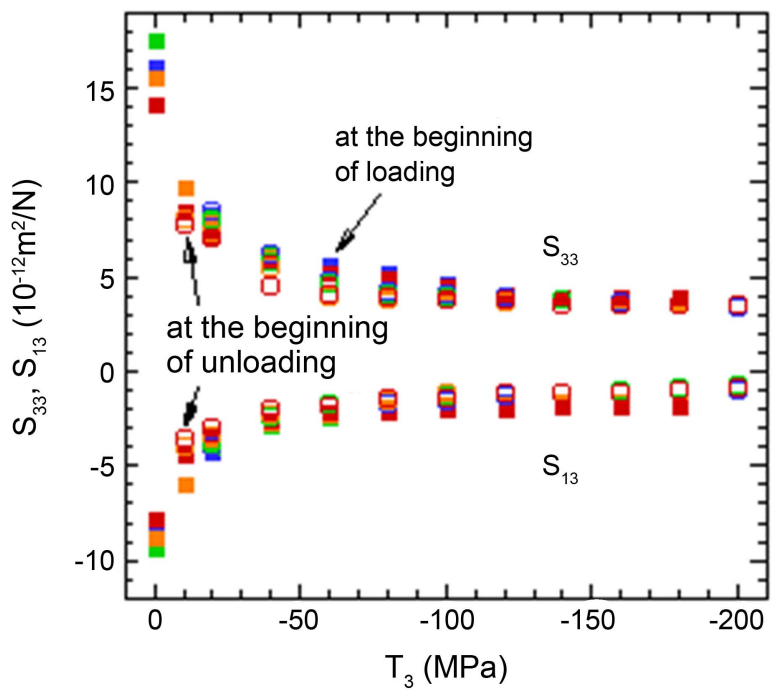

(b)

Fig. 4. Evaluated (a) piezoelectric and (b) compliance coefficients plotted versus compressive stress at four temperatures 20 , 50,80 , and $110^{\circ} \mathrm{C}$.

슷한 방법으로 접선을 그린 후 그 접선의 기울기로부터 같은 방법을 적용하여 구한다. Fig. 3(a)와 (b)에 보여주지 는 않았지만 유사한 실험을 $10 \mathrm{MPa}$ 에서도 수행하였으며 그 결과도 다음 절 논의에 포함하였다.

\section{2. 응력에 따른 재료상수의 변화}

앞 절에서 계산한 압전계수와 탄성 유연계수의 인가된 압축응력의 크기에 따른 변화를 Fig. 4에 그렸다. 목표응 력에 도달한 이후 응력이 제거되기 시작하는 순간에 구 한 재료상수는 속이 빈 원으로 표시했고, 응력이 0 에서 증가하기 시작하는 순간에 구한 재료상수는 속이 채워진 네모로 표시했다. 모든 재료상수에 대하여 전자의 경우에 


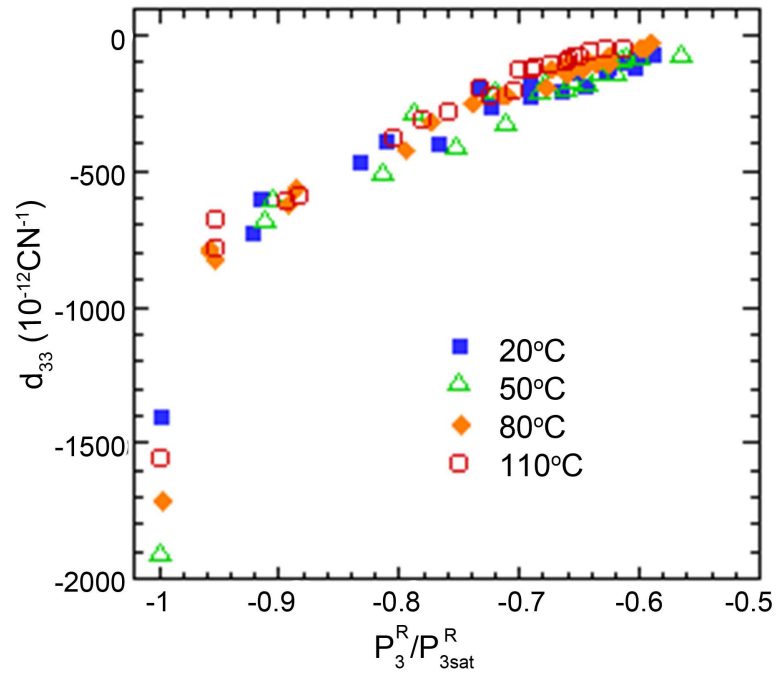

(a)

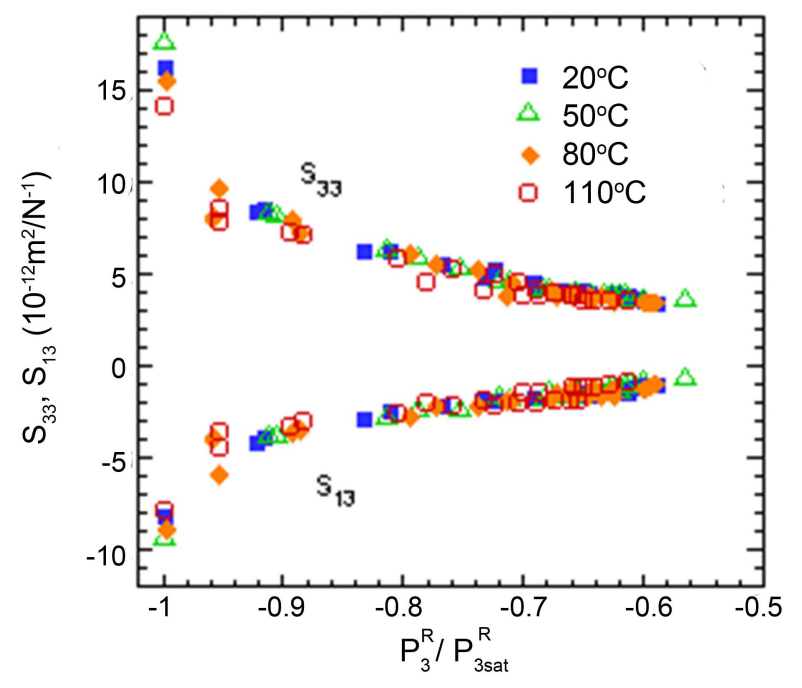

(b)

Fig. 5. Evaluated (a) piezoelectric and (b) compliance coefficients plotted versus relative remnant polarization at four temperatures $20,50,80$, and $110^{\circ} \mathrm{C}$.

구한 재료상수의 크기가 후자의 경우에 구한 값들의 크 기보다 약간 작은 것을 알 수 있었으나 응력의 크기에 따 른 변화에 비하면 무시할 수 있는 정도였다. 응력의 크기 가 증가하면 모든 압전계수의 크기가 0 으로 수렴하고 탄 성유연계수 역시 작은 값으로 수렴하는 것을 볼 수 있다. 압축응력의 크기가 증가할수록 두께 방향으로 향해 있던 도메인들은 더 불안정하게 되고 두께에 수직한 방향의 도 메인들은 더 안정하게 된다. 그 결과 압축응력이 증가함 에 따라 초기에 종방향으로 향해 있던 도메인들이 두께 에 수직한 횡방향으로 스위칭된다. 그 스위칭으로 인해 두께 방향으로의 분극의 크기가 감소하게 되며 압전계수 의 크기가 감소한다고 이해할 수 있다. Fig. 4의 재료특 성치는 2장에서 시편 제조사가 제공하는 재료특성치와 상

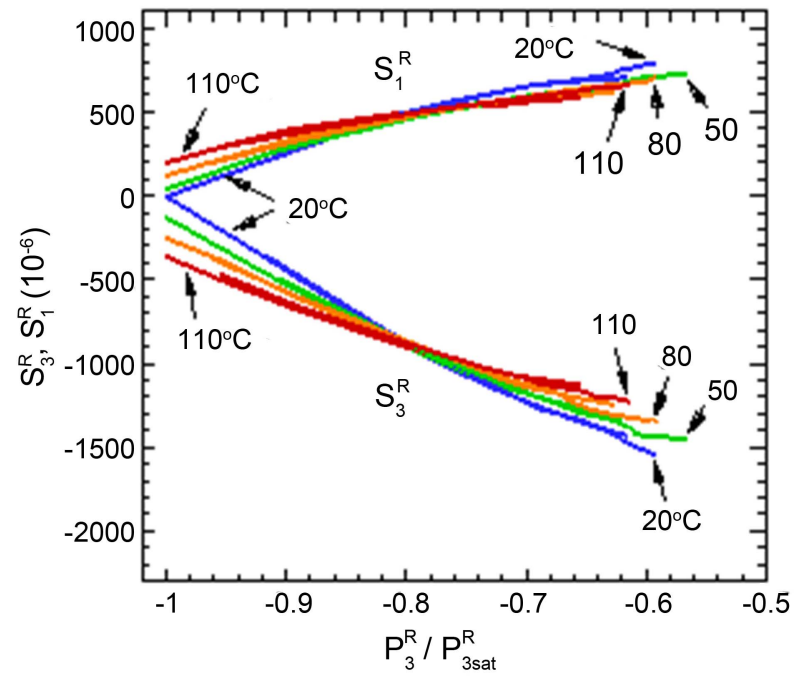

Fig. 6. Longitudinal and transverse remnant strains plotted versus relative remnant polarization at four temperatures 20,50 , 80 , and $110^{\circ} \mathrm{C}$.

당히 다른데 이는 측정방법의 차이에 기인한다고 판단된 다. 제조업자의 경우 동적공진법 (dynamic resonance method) 을 사용하였다. 온도에 따른 변화는 그림에서 일관된 뚜 렷한 차이를 발견할 수 없었다.

\section{3. 상대잔류분극에 따른 재료상수의 변화}

서로 다른 온도에서의 재료상수들의 변화를 비교하기 위하여 소위 상대 잔류분극 (relative remnant polarization) 이라는 변수를 도입한다. ${ }^{11)}$ 상대 잔류분극 $P_{3}^{R} / P_{3 s a t}^{R}$ 은 어 떤 온도에서의 잔류분극 $P_{3}^{R}$ 을 그 온도에서의 포화분극 의 크기 $P_{3 s a t}^{R}$ 로 나눈 값이다.

$P_{3}^{R}$ 이 음수일 때는 상대잔류분극 역시 음수가 되며, 그 값은 -1 에서 +1 까지 변한다. $P_{3}^{R} / P_{3 s a t}^{R}= \pm 1$ 은 각각 양과 음의 방향으로 분극처리된 상태에 대응한다. 압축하중에 의한 내부 도메인 구조의 변화는 상대 잔류분극을 이용 하여 나타낼 수 있다. Fig. 4에 보인 재료상수의 값들을 상대 잔류분극에 대해서 Fig. 5와 같이 다시 그렸다. $P_{3}^{R} / P_{3 s a t}^{R}=-1$ 일 때를 제외한 모든 상대 잔류분극 범위에 서 온도에 상관없이 압전계수와 탄성유연계수의 값들이 상대 잔류분극에 비례함을 알 수 있다. $P_{3}^{R} / P_{3 s a t}^{R}=-1$ 때 재료상수 값들이 상대 잔류분극과의 비례관계에서 벗어 나는 것은 최초의 압축응력파의 크기가 작고 따라서 재 료상수를 구하기 위해 접선을 그릴 때 충분히 믿을 만한 기울기를 가지는 접선을 그리기 어렵다는 점 때문이라고 생각된다.

마지막으로 종방향 및 횡방향 잔류변형률 $S_{3}^{R}, S_{1}^{R}$ 의 상 대잔류분극 $P_{3}^{R} / P_{3 s a t}^{R}$ 에 대한 변화가 Fig. 6 에 있다. Fig. 6 를 보면, 일정한 온도에서 잔류변형률은 상대 잔류분극에 비례하는 것을 알 수 있다. 종방향 잔류변형률의 경우 그 
비례상수, 즉 $S_{3}^{R}$ 선도의 기울기는 온도에 따라 증가하지 만, 횡방향 잔류변형률의 경우 $S_{1}^{R}$ 선도의 기울기는 온도 에 따라 감소하는 것을 볼 수 있다. 그 결과 상대잔류분 극이 상대적으로 작은 값일 때, 즉, 압축응력이 상대적으 로 작은 크기일 때는 $S_{3}^{R}$ 은 온도에 따라 감소하고 $S_{1}^{R}$ 은 증가하는 반면, 상대잔류분극이 상대적으로 큰 값일 때, 또는 압축응력이 상대적으로 클 때는 $S_{3}^{R}$ 은 온도에 따라 증가하고 $S_{1}^{R}$ 은 감소함을 볼 수 있다. 이는 압축하중에 따 른 도메인 스위칭으로 설명할 수 있다. 분극처리 상태에 서는 종방향의 열팽창계수가 음수이고 횡방향으로의 열 팽창계수가 양수이며 이는 Fig. 6에서 좌측부분, 즉 압축 응력이 작을 때의 거동과 일치한다. 반면 압축하중이 충 분히 클 경우, 종 방향으로 향해 있던 도메인들의 극성이 횡 방향으로 향하게 되며 그 결과 시편의 종 방향으로의 열팽창계수는 양수가 되고 횡 방향으로의 열팽창계수는 음수가 되어 Fig. 6의 우측부분에 보인 거동을 하게 된다 고 이해할 수 있다.

\section{4. 결 론}

본 연구에서는 분극처리된 PZT 시편에 크기가 점진적 으로 증가하는 충격파 형태의 압축하중을 인가할 때 계 측된 비선형 재료거동으로부터 압전계수와 탄성유연계수 및 잔류변형률과 잔류분극밀도의 변화를 구하였다. 압전 계수와 탄성유연계수는 상대잔류분극에 대해서 온도에 상 관없이 근사적으로는 선형으로 변하는 것을 관찰하였다. 잔류변형률은 상대 잔류분극에 대해서 선형관계를 가지 지만 그 변화율은 온도에 따라 다르다. 이는 압축응력에 의해 발생한 도메인 스위칭으로 인한 재료 내부구조의 변 화로 설명할 수 있다.

\section{Acknowledgment}

이 논문은 2012년도 서울시립대학교 연구년교수 연구 비에 의하여 연구되었습니다.

\section{REFERENCES}

1. J. E. Huber and N. A. Fleck, "Multi-axial Electrical Switching of a Ferroelectric: Theory Versus Experiment," J. Mech. Phys. Solids, 49 785-811 (2001).

2. S. J. Kim, "A Constitutive Model for Thermo-electromechanical Behavior of Ferroelectric Polycrystals Near Room Temperature," Int. J. Solids Struct., 48 1318-29 (2011).

3. K. G. Webber, E. Aulbach, T. Key, M. Marsilius, T. Granzow, and J. Rödel "Temperature-dependent Ferroelastic Switching of Soft Lead Zirconate Titanate," Acta Mater., 57 4614-23 (2009).

4. M. Selten, G. A. Schneider, V. Knoblauch, and R. M. McMeeking, "On the Evolution of the Linear Material Properties of PZT During Loading History-an Experimental Study," Int. J. Solids Struct., 42 3953-66 (2005).

5. Q. D. Liu and J. E. Huber., "State Dependent Linear Moduli in Ferroelectrics," Int. J. Solids Struct., 44 5635-50 (2007).

6. D. Zhou, R. Wang, and M Kamlah, "Determination of Reversible and Irreversible Contributions to the Polarization and Strain Response of Soft PZT Using the Partial Unloading Method," J. Euro. Ceram. Soc., 30 2603-15 (2010).

7. S. J. Kim and Y. S. Kim, "State Dependent Pyroelectric and Thermal Expansion Coefficients in a PZT Wafer," Ceram. Int., 36 2189-96 (2010).

8. Y. S. Kim and S. J. Kim, "Evolution of Linear Moduli and Remanent State Variables during Polarization Reversal in a Lead Zirconate Titanate Wafer at Various Temperatures," Jap. J. Appl. Phys., 50 031503-1-6 (2011).

9. S. J. Kim, J. H. Kim, and C. H. Lee, "Domain Switching and Creep Behavior of a Poled PZT Wafer under Through-thickness Electric Fields at High Temperatures," Acta Mater., 58 2237-49 (2010).

10. D. W. Ji and S. J. Kim, “Temperature-dependent Ferroelastic Switching of Ferroelectric Ceramics and Evolution of Linear Material Properties," Acta Mater., 61 1-11 (2013).

11. S. J. Kim and D. W. Ji, "Temperature-dependent Compressive Creep of Ferroelectric Ceramics and Evolution of Remnant State Variables," J. Euro. Ceram. Soc. Submitted, (2013). 